\title{
A CONCEPÇÃO DOCENTE EM UMA EXPERIÊNCIA DE EDUCAÇÃO INFANTIL INCLUSIVA: UM ESTUDO DE CASO
}

\author{
LA CONCEPCIÓN DOCENTE EN UNA EXPERIENCIA DE EDUCACIÓN INFANTIL \\ INCLUSIVA: UN ESTUDIO DE CASO
}

\section{THE TEACHING CONCEPTION IN AN INCLUSIVE CHILD EDUCATION EXPERIENCE: A CASE STUDY}

\author{
Mariana Picchi SALTO ${ }^{1}$ \\ Relma Urel Carbone CARNEIRO ${ }^{2}$
}

RESUMO: Com a efetividade da Educação Infantil inclusiva, são disponibilizadas as condições necessárias para que as crianças se desenvolvam integralmente, assim como ocorre a formação de uma nova geração, livre de preconceitos sobre o outro. Nesse contexto, através de um estudo de caso, a presente pesquisa teve como objetivo geral investigar se o trabalho pedagógico contribui para a educação inclusiva de um aluno com a síndrome Cri du Chat. Para isso, foi realizada uma entrevista semiestruturada com uma pedagoga da rede municipal de ensino, em uma cidade do interior paulista. Os dados obtidos foram analisados segundo a análise de conteúdo. É concluído que a formação docente para a educação inclusiva é, ainda, muito precária, o que faz com que os docentes não consigam atuar de forma a garantir a inclusão em sala de aula.

PALAVRAS-CHAVE: Educação inclusiva. Educação infantil. Concepções docentes.

RESUMEN: Con la efectividad de la educación infantil inclusiva, están disponibles las condiciones necesarias para que los niños se desarrollen integramente, así como ocurre la formación de una nueva generación, libre de preconceptos sobre el otro. En este contexto, atraves de un estudio de caso, la presente investigación tuvo como objetivo general investigar si el trabajo pedagógico contribuye a la educación inclusiva, de un alumno con el síndrome Cri du Chat. Para eso, fue realizada una entrevista semiestructurada con una pedagoga, de la red municipal de enseñanza, en una ciudad del interior paulista. Los datos obtenidos fueron analizados según el análisis de contenido. Y concluyó que una formación docente para la educación inclusiva es, aún, muy precaria, lo que hace que los docentes no logren actuar de forma que garantice la inclusión en el aula de clase.

PALABRAS CLAVE: Educación inclusiva. Educación infantil. Concepciones docentes.

${ }^{1}$ Universidade Estadual Paulista (UNESP), Araraquara - SP - Brasil. Discente do Programa de Pós-graduação em Educação Escolar. ORCID: <https://orcid.org/0000-0002-2602-3206>. E-mail: mariana.picchi@hotmail.com ${ }^{2}$ Universidade Estadual Paulista (UNESP), Araraquara - SP - Brasil. Docente do Programa de Pós-graduação em Educação Escolar. ORCID: <https://orcid.org/0000-0002-8961-3617>. E-mail: relma.urel@unesp.br 
ABSTRACT: With the effectiveness of inclusive child education, the conditions necessary for children to fully develop are made available, as is the formation of a new generation, free of prejudgments over the other. In this context, through a case study, the present research had as general objective to investigate if the pedagogical work contributes to the inclusive education of a student with the Cri du Chat syndrome. For this, a semi-structured interview was performed with a pedagogue, from the municipal teaching network, in a city in the interior of São Paulo. The data were analyzed according to the content analysis. It is concluded that teacher training for inclusive education is still very precarious, which means that teachers are unable to act in order to ensure inclusion in the classroom.

KEYWORDS: Inclusive education. Child education. Teaching conceptions.

\section{Introdução}

Partindo do pressuposto de que a criança é reconhecida como um sujeito social e de direitos, é emergente a necessidade de garantir, através da instituição escolar, as condições necessárias para que ela possa se desenvolver o mais plenamente possível, dentro de suas capacidades, limitações e potencialidades. A este respeito, a Lei de Diretrizes e Bases da Educação Nacional enfatiza que o desenvolvimento integral da criança seja feito "[...] em seus aspectos físicos, psicológicos, intelectual e social” (BRASIL, 1996, p. 11).

A escola deve ser um espaço que valorize a diversidade dos sujeitos e que utilize de propostas e alternativas para que essas crianças sejam verdadeiramente incluídas, valorizadas e acolhidas. Ao contrário, serão apenas mais situações cotidianas em que suas potencialidades não são reconhecidas, tampouco estimuladas ao longo da vivência escolar. Carneiro (2012) explica que é na Educação Infantil que a inclusão escolar deve começar, através do acesso a um ambiente que ofereça "[...] também aos alunos com deficiência, desde a mais tenra idade, condições de se desenvolverem como cidadãos de fato e de direito" (CARNEIRO, 2012, p. 86).

Ainda, ao promover a Educação Infantil inclusiva poderá ocorrer a formação de uma nova geração livre de preconceitos para com o outro (CARNEIRO, 2012), uma vez que tal geração trará em si uma formação ética, com a essência voltada em reconhecer o outro como sujeito (TEDESCO, 1998).

Há uma possibilidade de que as gerações futuras possam romper com a neutralidade em relação às diferenças, pois terão valores como responsabilidade, tolerância, justiça e solidariedade, constituindo o corpo central de sua formação e refletindo na sociedade, como um todo (TEDESCO, 1998). 
Tendo em vista esses aspectos, a presente pesquisa teve como objetivo geral investigar se o trabalho pedagógico contribui para a educação inclusiva, de um aluno com a síndrome Cri du Chat.

Para Machado et al. (2007), tal síndrome é proveniente de uma má-formação de origem genética rara, com incidência de 1 a cada 50.000 nascimentos no mundo. A alteração cromossômica é detectada durante a gravidez com exames citogenéticos muito específicos, o que, consequentemente, dificulta o diagnóstico pré-natal.

Muitos pais apenas descobrem a síndrome no nascimento da criança, através do choro do bebê similar ao de um gato, característico da própria síndrome, além de outras características que também podem ser presentes, facilitando o diagnóstico durante o primeiro ano de vida da criança: o baixo peso ao nascer, dificuldade de sucção, microcefalia, rosto arredondado, assimetria facial, orelha de implantação baixa, distanciamento dos olhos (hiperlorismo ocular), comprometimento locomotor e neurológico, sendo que algumas características podem se modificar conforme a idade da criança avança, uma vez que "o fenótipo da criança muda com a idade" (MACHADO et al., 2007, p. 1670):

[...] a idade de confirmação de diagnóstico mais precisa é por volta do primeiro ano de vida, sendo o primeiro mês mais fácil sua confirmação, enfatizando também que após os seis anos de vida essa confirmação é mais difícil, devido às modificações das principais características mais frequentes (MAINARDI, 2006 apud MACHADO et al., 2007, p. 1669).

Sobre a deficiência mental, os estudos evidenciam que é persistente na maioria dos casos, mas com a "[...] educação especializada e a estimulação precoce” (MACHADO et al., 2007, p. 1670), o desenvolvimento da criança pode aumentar, uma vez que a oferta de estímulos cognitivos, motores e pedagógicos podem propiciar a ela melhores condições de vida, com a superação de suas limitações (MACHADO et al., 2007).

\section{Método}

A presente pesquisa se insere no campo da pesquisa qualitativa, definida como "uma atividade situada que localiza o observador no mundo. Consiste em um conjunto de práticas materiais e interpretativas que dão visibilidade ao mundo" (DENZIN; LINCOLN, 2006, p. 17). 
Através da coleta de dados empíricos, “[...] que descrevem momentos e significados rotineiros e problemáticos na vida dos indivíduos" (DENZIN; LINCOLN, 2006, p. 17), a pesquisa qualitativa possibilita investigar os aspectos da realidade que estão contidos em um universo de significados, valores, atitudes e crenças que não podem ser classificados com base nos dados quantitativos (MINAYO, 2007).

A escolha da metodologia de estudo de caso ocorreu uma vez que a observação detalhada de um contexto singular possibilitaria estudar uma situação que já ocorreu e que gerou um resultado específico, para o qual era necessário obter as causas ou os fatores que o antecederam. Com essa metodologia de coleta de dados, ocorre a "[...] construção de uma teoria explicativa (modelo) para a realidade observada. Este modelo será, então, objeto de outras pesquisas, envolvendo outros casos, de modo a testar sua generalidade" (ROSA, 2013, p. 73).

Foi realizada uma entrevista semiestruturada com uma pedagoga da Educação Infantil, em uma escola municipal, situada em uma cidade do interior paulista. Através de perguntas simples, era esperado obter informações acerca das maneiras pelas quais se dava seu trabalho pedagógico com um aluno com a síndrome Cri $d u$ Chat, em uma sala de aula comum, em um contexto de Educação Infantil inclusiva.

Durante esse processo de coleta de dados, foi utilizado um gravador, possibilitando à pesquisa maior exatidão nos dados coletados, por ser uma fonte que permite alcançar com maior amplitude os resultados, sem que eles possam ser esquecidos e/ou alterados, além de permitir que até os aspectos mais subjetivos possam ser, posteriormente, analisados (BELEI et al., 2008).

A análise dos dados foi feita a partir da análise de conteúdo, uma técnica que permite produzir inferências acerca de dados verbais, ao "[...] conhecer aquilo que está por trás das palavras" (BARDIN, 1977, p. 44).

\section{Resultados e Discussão}

No processo de análise, as respostas da pedagoga entrevistada foram remanejadas em dados organizados, através do processo de categorização, no qual foram estabelecidas categorias a posteriori: “[...] categorias vão sendo criadas, à medida que surgem nas respostas, para depois serem interpretadas à luz das teorias explicativas" (FRANCO, 2005, p. 60). 
Na primeira categoria, titulada de "Inclusão x Socialização", foram agrupadas as respostas que evidenciam que a escola é tida como um espaço responsável apenas para a socialização do indivíduo com deficiência intelectual. Para a pedagoga, a escola permitia à criança "o convívio, o contato, a parte social mesmo". Capellini e Rodrigues (2009) explicam que a socialização é realmente importante para a promoção da inclusão, desde que seja reconhecida como um facilitador do processo de aprendizagem.

A integração de todos os alunos pode ser responsável por permitir a criação de um ambiente acolhedor dentro da sala de aula. Consequentemente, é mais fácil para o aluno o desejo de construir a sua aprendizagem, além de permitir, também, a construção das mais diversas habilidades (CAPPELINI; RODRIGUES, 2009).

Entretanto, em um outro momento da entrevista, a pedagoga entrou em contradição quanto à questão da socialização. Para ela, nas atividades em grupo, o aluno ainda permanecia excluído, já que as crianças “[...] não chegavam muito perto”. A própria pedagoga não promoveu a socialização, quando, em uma brincadeira de roda, por exemplo, relatou que o estudante não participou em conjunto com os colegas, e sim dando uma mão para ela e a outra para a auxiliar: "[...] ele dá a mão pra mim e pra auxiliar e aí ele brinca".

Para Macedo (2008), a socialização ocorre em meio às desvantagens, de qualquer maneira que seja promovida, porque ainda há uma tensão gerada pelas diferenças sociais e/ou biológicas entre os sujeitos. A socialização efetivamente ocorrerá quando o aluno públicoalvo da educação especial for visto pelos outros e por si mesmo como um sujeito "[...] implicado e protagonista de sua própria história” (MACEDO, 2008, p. 131).

O processo de socialização é difícil, uma vez que elas crescem e se desenvolvem em um contexto afetivo e social pouco estimulador. $\mathrm{O}$ meio social acaba por promover elementos dificultadores para que realmente tenham uma inserção social, uma vez que são, na maior parte, rotuladas por terceiros como incapazes e ineficientes (MACEDO, 2008).

A pedagoga entrevistada relatou, em certo momento, palavras que vão ao encontro da explicação de Macedo (2008), ao dizer que as crianças com deficiência intelectual não conseguem se desenvolver plenamente, sendo "mais fácil" trabalhar a inclusão com outros tipos de deficiência.

Ao ter essa visão, os docentes, no geral, silenciam tanto a socialização da criança como a própria construção de sua aprendizagem. Além disso, negligenciam quaisquer potencialidades que essas crianças poderão ter, uma vez que deixam de fornecer o mínimo de estímulo ou dedicação, acreditando que "[...] ensinar crianças com necessidades especiais é 
uma tarefa para especialistas em educação especial" (CAPELLINI; RODRIGUES, 2009, p. $358)$.

Para a inclusão escolar acontecer, é necessária uma mudança de atitude dos docentes para que haja, posteriormente, uma mudança de atitude nas crianças. É somente ao valorizar o aluno dentro de suas limitações e necessidades que poderão fornecer a ele condições para “[...] diminuição da ansiedade e depressão, com ganhos emocionais e funcionais, e melhora do auto-conceito, auto-imagem, auto-estima e auto-confiança" (MACEDO, 2008, p. 135).

$\mathrm{Na}$ segunda categoria, "O papel docente", foram agrupados os dados referentes à prática pedagógica da pedagoga em sala de aula e se havia ligação desta com a promoção da inclusão escolar. No decorrer da entrevista, falas como: “[...] Eu tenho muito medo"; “[...] Eu tinha muita dúvida", denunciavam a insegurança que possuía quanto ao que deveria ser feito para que agisse em prol da inclusão escolar.

Parte dessa insegurança tem em sua gênese a precária formação docente para a inclusão escolar. No caso da pedagoga entrevistada, suas especializações eram específicas para a alfabetização, o que denota certo desconhecimento quanto à necessidade da promoção da inclusão escolar e quais os caminhos a serem seguidos nessa perspectiva.

Para Sant'Ana (2005), a falta da formação adequada dos docentes para que consigam atender às necessidades educativas especiais é um sério problema, uma vez que, na maioria dos casos, os cursos formativos carecem da percepção de que é preciso a instrumentalização dos docentes quanto à parte teórica, mas, tão importante quanto, é o encorajamento para que eles adotem, como prática constante, sérias reflexões acerca de sua prática pedagógica, crenças e de que forma podem aprimorar o ensino que é oferecido em sala de aula.

Dessa forma, questionar esse campo é tão urgente quanto necessário, já que “[...] independente de como está a formação do professor, o aluno com NEE continuará chegando às escolas, estejam elas preparadas ou não" (TOLEDO; MARTINS, 2009, p. 4130).

O despreparo ainda pode ser visto quando a pedagoga entrevistada relatou que "[... a gente precisava era de um profissional que viesse falar 'faz assim, faz daquele jeito' na sala de aula, pra gente se sentir mais preparada, sabe?", o que reiterou a insegurança e despreparo docente, convergidos em uma necessidade de transmitir a responsabilidade de educar alunos público-alvo da educação especial para outro profissional, mais preparado.

Sant'Ana (2005) explica que a formação continuada favorece a implementação da proposta inclusiva. Entretanto, ela apenas surtirá efeito quando estiver alinhada com o compromisso do docente em realmente trabalhar para a concretização dessas mudanças, 
melhorando as condições do ensino e oferecendo a ele o suporte de outros profissionais, inclusive para auxiliá-lo em seu trabalho.

O envolvimento de todos os membros da equipe escolar e profissionais da saúde é fundamental para que haja uma articulação entre o que já foi realizado e o que pode ser feito, de maneira mais ampla, durante o planejamento de ações e de programas, sendo essa uma “[...] tarefa de construir uma escola pronta a atender a todos os indivíduos, sem discriminação" (SANT’ANA, 2005, p. 229). Com isso, trabalho com uma equipe pedagógica abrange a

[...] divisão do trabalho, reforço mútuo, continuidade ao longo do curso, descompartimentação, multiplicidade de visões sobre os alunos e de estratégias de intervenção, acúmulo e partilha de experiências, etc. (PERRENOUD, 2001, p. 139).

Quando o docente se reconhecer como "[...] o elo de uma corrente" (PERRENOUD, 2001, p. 136) que se liga aos os pais e à equipe pedagógica, compreenderá que está em suas mãos o poder de oportunizar uma escola inclusiva ao romper com o ensino mecanizado em que está habituado e, finalmente, promover o processo de ensino-aprendizagem que esteja a serviço de todos os seus alunos, incluindo os mais desfavorecidos.

A terceira categoria, "Concepção de aprendizagem", evidenciou os aspectos direcionados à aprendizagem do aluno com síndrome do Cri $d u$ Chat e de que forma a presença do laudo médico pôde contribuir sobremaneira para a atribuição do fracasso escolar.

Durante a entrevista, a pedagoga relatou que o diagnóstico da síndrome ocorreu logo cedo, e com a efetivação do laudo médico, os pais e a própria equipe pedagógica passaram a acreditar que havia defasagem na aprendizagem da criança, de forma que ele não conseguia compreender as atividades, nem desenvolver sua autonomia e ser capaz de aprender: "[...] Ele não tem compreensão... ele não tem. Porque a própria síndrome tem um atraso mental”.

A imposição de rótulos e de julgamentos que as pessoas fazem, muitas vezes em virtude de características tidas como desviantes do padrão da normalidade imposto pela sociedade, acaba por estigmatizar o indivíduo e deixá-lo à própria sorte no que tange à aprendizagem (GIROTO; CASTRO, 2011).

Isso ocorre pois as expectativas e julgamentos dos docentes para com essas crianças podem interferir no desempenho escolar positivamente, quando apresenta o julgamento de serem bons alunos; ou negativamente, se as expectativas sobre elas são, também, negativas: 
[...] ao esperar menos dos alunos considerados como aqueles com distúrbios, o professor acabará por investir menos em sua aprendizagem. Isso pode repercutir também no comprometimento de aspectos relativos às relações de ensino e de aprendizagem, em sala de aula, e à autoestima dessas crianças, que passam a se considerar incapacitadas para a construção efetiva de práticas de leitura e de escrita e a incorporar tal incapacidade como característica própria e pessoal (GIROTO; CASTRO, 2011, p. 443).

Com isso, a pedagoga assumiu que "[...] eu tinha dó dele aqui na sala", e deixou de reconhecer em muitas coisas que a criança faz pequenos indícios de aprendizagem e de desenvolvimento, os quais deveriam, por sua vez, serem encorajados e estimulados: “[...] ah, ele sabe letrinhas; "[...] ele vê um sapo e ele levanta e vem 'apo apo apo"”; "[...] hoje ele falou 'alalo' que é o cavalo que tinha no livro".

Capellini e Rodrigues (2009) explicam que ao subestimar o que a criança é capaz de realizar, o docente acaba por submetê-la a programas educativos reduzidos, caracterizados pela falta de desafios e de estímulos, justamente por não crer em quaisquer potencialidades que a criança tenha. E é uma realidade que acaba por perpetuar, ainda mais, a ideia de que nada pode ser feito para reverter esse quadro, já que

[...] existem crianças dotadas, que terão sucesso na escola, e outras menos dotadas, que devem resignar-se, se não ao fracasso, pelo menos a resultados medíocres que desembocarão em um destino sem glória (PERRENOUD, 2001, p. 18).

Nesse sentido, as crianças sofrem um processo chamado de "institucionalização invisível" (MOYSÉS, 2001 apud GIROTO; CASTRO, 2011), em que permanecem no espaço físico da sala de aula, mas são excluídas do processo de ensino e de aprendizagem. A proposta de escola inclusiva considera que cada aluno aprende em seu ritmo, seguindo seus próprios modos de pensamento e que ao docente cabe propiciar situações didáticas diferenciadas no momento mais adequado, quando o aluno querer e poder investir nelas (PERRENOUD, 2001).

Ao aceitar que "[...] nada se determina no momento do nascimento ou antes dos seis anos" (PERRENOUD, 2011, p. 135), o professor poderá valorizar todos os progressos de seus alunos, inclusive daqueles que apresentam mais dificuldades e convencê-los de que eles podem aprender. Dessa forma, o princípio da inclusão poderá ser efetivado ao

[...] exigir uma nova escola e uma nova sociedade, com atitudes e posturas diferentes, de maneira a garantir o direito ao acesso e permanência na escola e o direito de ser diferente sem ser rotulado, discriminado ou segregado (CAPELLINI; RODRIGUES, 200, p. 357). 
A quarta categoria, "Igualdade x Equidade", evidenciou concepções de senso comum acerca da promoção de uma escola inclusiva a partir do pressuposto da inclusão como a igualdade entre os alunos, tratando-os de forma igualitária, conforme evidenciado no trecho a seguir: "Eu trato ele igual como todas as crianças".

Haddad (2007) explica que a confusão entre os termos não é recente. Há muito, a noção de escola inclusiva se relaciona à necessidade de tratar os estudantes de forma igualitária. Os documentos oficiais, como a Constituição Federal (BRASIL, 1988), o Estatuto da Criança e do Adolescente (BRASIL, 1990) e a Lei de Diretrizes e Bases da Educação Nacional (BRASIL, 1996), reafirmam a igualdade de condições para o acesso e permanência de alunos com deficiência em classes comuns do ensino regular. Entretanto, tais pressupostos não são suficientemente concisos a ponto de fundamentarem a organização de um sistema educacional verdadeiramente inclusivo, pois contribuem para a crença docente de que a igualdade sustenta a inclusão escolar (OLIVEIRA; LEITE, 2007).

A pedagoga entrevistada evidenciou que dessa forma contribuiria para o sucesso da criança na escola, pois defendia a ideia de "tem que ser igual" o tratamento que dá para seus alunos, uma vez que desejava que ele fosse igual às outras crianças: “[...] já quero ele igual a todo mundo".

Ao construir na escola práticas pautadas na igualdade, cuja essência considera que o ensino deveria ser homogêneo, os próprios docentes passam a crer que "[...] os alunos são supostamente iguais - em relação a faixa etária, ritmo de aprendizagem, nível escolar, etc.” (OLIVEIRA; LEITE, 2007, p. 517) e contribuem para legitimar a desigualdade ao neutralizar e não reconhecer as diferenças entre os indivíduos, tampouco ao não reconhecer suas necessidades mais urgentes.

Uma escola inclusiva, por sua vez, é pautada no princípio da equidade, “[...] em que respeitar a diferença não é se opor à igualdade e sim garantir direitos iguais para atender às necessidades específicas de cada um, considerando que todos são diferentes" (OLIVEIRA; LEITE, 2007, p. 517). Ainda, a equidade

[...] postula o favorecimento de condições diferenciadas para suprir as desigualdades sociais, culturais e econômicas, daqueles que se encontram em situação de desvantagem. [...] isso se deve dar a partir das adaptações e da disponibilização de suportes necessários para participação de todos na vida doméstica; escolar; social; profissional e econômica (OLIVEIRA; LEITE, 2007 , p. 517, grifos nossos). 
Haddad (2007) complementa a definição de equidade quando explica que esta enfatiza um sistema educativo que compense as desigualdades de ritmos de ensino e de aprendizagem entre cada aluno e, ainda, que gere as condições necessárias - tais como: “[...] derrubar barreiras arquitetônicas, readequar o currículo, adaptar os conteúdos, usar novas metodologias, capacitar professores, etc.” (GUHUR, 2003, p. 42) - para diminuir as desigualdades entre os estudantes, quaisquer que sejam elas.

A este respeito, a pedagoga entrevistada apresentou uma noção muito simplista em relação à adaptação. Ela relatou que em algumas atividades promoveu as adaptações, mas nem sempre esse processo foi planejado e/ou executado com sucesso: “[...] às vezes eu penso antes, hoje eu preparei algo antes pra ele estar fazendo, mas às vezes no dia eu dou igual e aí no momento eu vejo se dá pra adaptar ou não".

É preciso que o docente se atente a todos os alunos, incluindo aqueles que têm maiores limitações e dificuldades. Não de forma a "colocá-los em uma relação de assistência ou de apoio pedagógico" (PERENOUD, 2001, p. 142), mas considerar que é importante acompanhá-los "continuamente, mesmo que seja de longe, mantê-los sobre o olhar do professor" (PERRENOUD, 2001, p. 143), pois só assim o docente poderá atentar-se para diferenciar as interações e as atividades, visando possibilitar aos estudantes, através da equidade, condições para seu desenvolvimento em sua amplitude.

Por fim, a quinta e última categoria, nomeada de "Senso comum e Preconceito", ressaltou os aspectos negativos em relação à concepção da criança com deficiência, enfatizando a reação em cadeia que pode ser estabelecida a partir da disseminação do preconceito que se instalou desde a gestão escolar, docentes e nas próprias crianças da escola.

No início do ano letivo, a diretora acreditava que a criança tinha um problema de baixa visão. Decorrido algum tempo, em uma conversa com os pais, foi constatado que ele possuía a síndrome do $C r i d u$ Chat, a qual é formada durante o período gestacional, em uma alteração genética. Entretanto, como toda síndrome, o desenvolvimento pode ser comprometido em menor ou em maior grau, sendo que, no segundo caso, a parte locomotora da criança, dentre outros aspectos, se torna mais comprometida (ALVES; FORMIGA; VIANA, 2011).

No caso da criança em questão, o comprometimento não foi tão severo, de forma que há locomoção e há o desenvolvimento intelectual, mesmo que pouco relatado pela pedagoga. Quando a equipe escolar se tornou ciente da realidade daquela criança, assumiu que seria um "problema", antes mesmo de conhecê-lo pessoalmente. 
Desde então, tanto a diretora da escola como a pedagoga acabaram por internalizar sentimentos de preconceito e de senso comum, uma vez que inferiram que o estudante não seria capaz de aprender e que seria, por si só, um problema para a escola. Embora a pedagoga relate, posteriormente, na entrevista, que "não tive nenhuma reação contrária, não", pode-se assumir que tal reação talvez não tenha sido reconhecida, mas o preconceito é manifestado de diversas formas, já que

[...] faz parte do nosso comportamento cotidiano. Frequentemente nos defrontamos com atitudes preconceituosas, seja em atos ou gestos, discursos e palavras. A sala de aula não escapa disso. E trabalhar com essa questão, ou mesmo com a intolerância, não está dentre as tarefas mais fáceis do professor (ITANI, 1998, p. 119).

Para Itani (1998), o preconceito não é uma manifestação isolada de um único indivíduo, mas é fundamentado no convívio social, dentro das representações sociais de critérios de normalidade e de uma opinião já cristalizada acerca de determinado assunto, pessoa ou objeto. É através da convivência dentro de um grupo social que são construídas e cristalizadas noções diversas acerca do que é considerado normal ou não para aquela sociedade, em um determinado momento histórico.

A escola, tal como um espaço social cujo interesse se alinha ao interesse da comunidade em que está inserida, com a reprodução das relações sociais vigentes, acaba por ser, também, uma instituição de seleção e de diferenciação social, ao promover práticas de exclusão que vão desde o comentário que evidencia a diferença entre os indivíduos, até o sarcasmo, riso, cochicho e o olhar da diferença (ITANI, 1998).

Quando em contato com os alunos, a pedagoga explicou a eles que haveria, na sala, "uma criança muito, mas muito especial”. Mesmo que tivesse bem-intencionada em acolhê-lo, o próprio discurso já realçou para as outras crianças que haveria uma seletividade entre eles, já que a criança recém-matriculada era especial, diferente dos demais. Consequentemente, nos primeiros dias letivos o tratamento seletivo foi reproduzido pelas crianças: "as crianças, no começo, ficavam, assim... porque ele era diferente, uma pessoa diferente na sala de aula... eles não chegavam muito perto".

Nesse sentido, foi evidenciado que "o preconceito, a discriminação, a estigmatização são comportamentos aprendidos" (CARNEIRO, 2012, p. 93). Da mesma forma em que a escola pode reproduzi-los, contribuindo para a formação de indivíduos preconceituosos e discriminadores, poderá romper com a neutralidade em relação ao outro e, como resultado, “[...] a criança pequena, ao adentrar em um espaço escolar em que as diferenças são bem 
vindas, vai aprender de forma natural a valorizar o outro por aquilo que ele é" (CARNEIRO, 2012, p. 93).

Além disso, é através da tolerância no cotidiano do processo educativo que se viabilizará o processo de “[...] admitir que o outro exista, enquanto tal, reconhecendo-o tal como é, e diferente de mim" (ITANI, 1998, p. 133). Ao reconhecer o outro como sujeito, haverá a promoção de uma formação ética nos educandos, em que todas as suas histórias são vistas como importantes e fundamentais para a construção da sociedade, como um todo.

\section{Considerações finais}

A pesquisa, por se tratar de um estudo de caso, apresenta limitações no sentido de não abranger a realidade de uma forma mais ampla. Apenas foi estudada uma situação específica, além do fato de que não é possível ocorrer generalização dos resultados observados, pois estes podem sofrer mudanças de acordo com a especificidade de cada situação.

A educação inclusiva foi correlacionada ao acesso do educando na escola, com a promoção da sua socialização. Com isso, foram promovidas concepções simplistas acerca do processo de inclusão escolar e dos meios para promovê-la, culminando na construção de um espaço escolar que legitima a desigualdade ao neutralizar as diferenças entre os indivíduos e, ainda, em um contexto afetivo e social pouco estimulador.

Não houve tanto comprometimento com a aprendizagem por parte dos diretores e docentes, os quais, comumente, creem que existem educandos que são capazes de alcançar o sucesso escolar, enquanto que outros não irão progredir, enfatizando o desejo de transmitir a responsabilidade de educar alunos público-alvo da educação especial para outro profissional, mais preparado.

Parte dessa realidade tem sua gênese na precariedade dos cursos formativos, de forma que a pedagoga entrevistada não teve o acesso a conhecimentos pertinentes para atuar frente a essa realidade, o que não a torna desqualificada para a profissão, mas que confirma a precariedade do processo formativo para a educação inclusiva.

Os cursos formativos não instrumentalizam, verdadeiramente, os docentes acerca de como a construção da escola inclusiva poderá ocorrer, através da reflexão da prática pedagógica, bem como da própria reflexão acerca do aprimoramento do ensino que oferecem em sala de aula. Também deve abranger a concepção de que a proposta da inclusão escolar se 
efetiva não na igualdade dos educandos, mas na equidade, com a promoção de condições de aprendizagem diferentes de acordo com a necessidade singular de cada um e propondo um sistema educativo que diminua as desigualdades entre os estudantes.

\section{REFERÊNCIAS}

ALVES, A. P. V.; FORMIGA, C. K. M. R.; VIANA, F. P. Perfil e desenvolvimento de crianças com síndromes genéticas em tratamento multidisciplinar. Revista Neurociência, v. 19 , n. 2, p. 254-293, 2011.

BARDIN, L. Análise de conteúdo. Lisboa: Edições 70, 1977.

BELEI, R. A. et al. O uso de entrevista, observação e videogravação em pesquisa qualitativa. Cadernos de Educação, Pelotas, n. 30, p. 187-199, 2008.

BRASIL. Constituição da República Federativa do Brasil. Brasília, DF: Senado Federal, 1988.

BRASIL. Dispõe sobre o Estatuto da Criança e do Adolescente e dá outras providências (Lei n. 8.069). Brasília, DF: Senado Federal, 1990.

BRASIL. Lei de diretrizes e bases da Educação Nacional (Lei n. 9.394). Brasília, DF: Senado Federal, 1996.

CAPELLINI, V. L. M. F; RODRIGUES, O. M. P. R. Concepções de professores acerca dos fatores que dificultam o processo da educação inclusiva. Educação, v. 32, n. 3, p. 355-364, 2009.

CARNEIRO, R. U. C. Educação inclusiva na educação infantil. Práxis Educacional, v. 8, v. 12, p. 81-95, 2012.

DENZIN, N. K.; LINCOLN, Y. S. O planejamento da pesquisa qualitativa: teorias e abordagens. 2ed. Porto Alegre: Artmed, 2006.

FRANCO, M. L. P. B. Análise de Conteúdo. 2. ed. Brasília: Liber Livro Editora, 2005.

GIROTO, C.R.M.; CASTRO, R.M. A formação de professores para a Educação Inclusiva: alguns aspectos de um trabalho colaborativo entre pesquisadores e professores da Educação Infantil. Revista Educação Especial, Santa Maria, v. 24, n. 41, p. 441-452, 2011.

GUHUR, M.L.P. Dialética inclusão-exclusão. Revista Brasileira de Educação Especial, v. 9, n. 1, p. 39-56, 2003.

HADDAD, S. Educação e exclusão no Brasil. Em questão, 2007. Disponível em: http://www.bdae.org.br/handle/123456789/2299. Acesso em: 03 jul. 2018. 
ITANI, A. Vivendo o preconceito em sala de aula. In: AQUINO, J. G. Diferenças e preconceito na escola: alternativas teóricas e práticas. São Paulo: Summus, 1998.

MACEDO, P. C. M. Deficiência Física Congênita e Saúde Mental. Revista SBPH, v. 11, n. $2,2008$.

MACHADO, N. C. S. S. et al. Principais características clínicas da síndrome Cri-du-Chat: Revisão de Literatura. Encontro latino americano de iniciação científica, v. 11, p. 16681671, 2007.

MINAYO, M. C. de. S. O desafio do conhecimento. 10. ed. São Paulo: HUCITEC, 2007.

OLIVEIRA, A. A. S.; LEITE, L. P. Construção de um sistema educacional inclusivo: um desafio político-pedagógico. Ensaio: Avaliação e Políticas Públicas em Educação, v. 15, n. 57, p. 511-524, 2007.

PERRENOUD, P. A Pedagogia na escola das diferenças: fragmentos de uma sociologia do fracasso. Porto Alegre: Artmed, 2001.

ROSA, P. R. da S. Uma introdução à pesquisa qualitativa em ensino de ciências. Campo Grande: Universidade Federal do Rio Grande do Sul, 2013.

SANT'ANA, I. M. Educação Inclusiva: Concepções de professores e diretores. Psicologia em Estudo, Maringá, v. 10, n. 2, p. 227-234, 2005.

TEDESCO, J. C. O novo pacto educativo. São Paulo: Ática, 1998.

TOLEDO, E. H. de.; MARTINS, J. B. A atuação do professor diante do processo de inclusão e as contribuições de Vygotsky. IX Congresso Nacional de Educação-EDUCERE/III Encontro Sul Brasileiro de Psicopedagogia-ESBP-ABPp. 2009. p. 4127-4138.

\section{Como referenciar este artigo}

SALTO, Mariana Picchi.; CARNEIRO, Relma Urel Carbone. A concepção docente em uma experiência de Educação Infantil inclusiva: um estudo de caso. Revista Ibero-Americana de Estudos em Educação, Araraquara, v. 14, n. esp. 1, p. 855-868, abr., 2019. E-ISSN: 19825587. DOI: 10.21723/riaee.v14iesp.1.12211

Submetido em: 06/08/2018

Aprovado em: 21/09/2018 